\title{
Effects of Securigera securidaca Extract on Lipolysis and Adipogenesis in Diabetic Rats
}

\author{
Ahmad Ghorbani, ${ }^{1}$ Reyhaneh Moradi Marjaneh, \\ Ziba Rajaei, $^{3}$ and Mousa-Al-Reza Hadjzadeh ${ }^{2}$ \\ ${ }^{1}$ Pharmacological Research Center of Medicinal Plants, School of Medicine, Mashhad University of Medical Sciences, \\ Mashhad 9177948564, Iran \\ ${ }^{2}$ Neurocognitive Research Center and Department of Physiology, School of Medicine, Mashhad University of Medical Sciences, \\ Mashhad 9177948564, Iran \\ ${ }^{3}$ Department of Physiology, School of Medicine, Isfahan University of Medical Sciences, Isfahan 7346181746, Iran
}

Correspondence should be addressed to Mousa-Al-Reza Hadjzadeh; hajzadehmr@mums.ac.ir

Received 30 April 2014; Revised 30 June 2014; Accepted 30 June 2014; Published 3 August 2014

Academic Editor: Patrizia M. Tarugi

Copyright (C) 2014 Ahmad Ghorbani et al. This is an open access article distributed under the Creative Commons Attribution License, which permits unrestricted use, distribution, and reproduction in any medium, provided the original work is properly cited.

\begin{abstract}
Diabetes mellitus is associated with dysregulation of adipose tissue metabolism and increased level of serum lipids. In our previous work we found that Securigera securidaca decreases cholesterol level in blood of diabetic rats. The present study was carried out to further investigate the effects of this plant on lipid metabolism, lipolysis, and adipogenesis, in diabetic rats. Female Wistar rats were rendered diabetic by intraperitoneal injection of streptozotocin. Retroperitoneal adipose tissue was removed from diabetic animals after seven days of streptozotocin injection. Effect of hydroalcoholic extract of S. securidaca seeds (100-800 $\mu \mathrm{g} / \mathrm{mL}) \mathrm{on}$ adipose tissue lipolysis was evaluated in ex vivo condition. Also, to evaluate adipogenesis, preadipocytes were isolated from adipose tissue and differentiated to adipocytes in the presence of the extract. The extract at concentration of $800 \mu \mathrm{g} / \mathrm{mL}$ decreased both basal and catecholamine-stimulated lipolysis $(P<0.05)$. Incubation of differentiating preadipocytes with $800 \mu \mathrm{g} / \mathrm{mL}$ of $S$. securidaca extract decreased intracellular lipid droplet accumulation as evaluated with Oil Red $\mathrm{O}$ staining $(P<0.001)$. The extract even at high concentrations had no effect on viability of preadipocytes. In conclusion, S. securidaca decreases lipolysis and adipogenesis without cytotoxicity, which makes it a good candidate for management of dyslipidemia and reduction of cardiovascular risks in diabetes.
\end{abstract}

\section{Introduction}

Diabetes mellitus is a major cause of hospitalization and still is one of the main diseases causing death and disability. The number of diabetic patients is markedly increasing in the world. According to the World Health Organization reports (October, 2013), 347 million people suffer from dia-betes worldwide and without urgent action, it will be the 7th cause of mortality in 2030. Diabetes is associated with impaired glucose and lipid metabolism and over time leads to microvascular and macrovascular complications such as cardiovascular diseases [1]. Dyslipidemia, a main risk factor of cardiovascular diseases, is often present in diabetic patients. Diabetic dyslipidemia is characterized by increased serum triglyceride and low density lipoprotein and decreased high density lipoprotein [2]. Patients with type-1 diabetes also undergo dysregulation of adipose tissue metabolism (lipolysis and lipogenesis) due to insulin deficiency.

Currently, statins, fibrates, niacin, and bile acid binding sequestrants are the most widely used medications for dyslipidemia. However, the clinical uses of these drugs are accompanied with unpleasant side effects such as myopathy and hepatic toxicity [3,4]. Moreover, despite aggressive drug therapy, a number of diabetic patients still experience coronary heart disease events [5]. Therefore, finding new hypolipidemic agents with better efficacy and lesser side effects is promising approach for management of diabetic dyslipidemia. 
Several studies have shown beneficial effects of natural agents on diabetes associated hyperglycemia and dyslipidemia [6, 7]. Securigera securidaca, an annual herb belonging to the Fabaceae family, is used in Iranian folk medicine for treatment of diabetes. Experimental studies have revealed that administration of $S$. securidaca seeds decreases blood glucose in normal and diabetic subjects [8-10]. Also this plant reduces the level of triglyceride and cholesterol in serum of high-fat fed rats [11]. In our previous work we showed that hydroalcoholic extract of Securigera securidaca seeds decreases serum cholesterol in diabetic rats [12]. This study was carried out to investigate effects of this extract on adipose tissue lipolysis and adipogenesis in diabetic rats.

\section{Materials and Methods}

2.1. Chemicals and Reagents. Dulbecco's modified Eagle's medium (DMEM) and fetal bovine serum (FBS) were purchased from Gibco (Carlsbad, CA). Streptozotocin (STZ) was obtained from Enzo Life Science (USA). Fatty acidfree bovine serum albumin fraction $\mathrm{V}$, glycerol assay reagent, isoproterenol, penicillin-streptomycin, type-II collagenase, 3-(4,5-dimethyl-2-thiazolyl)-2,5-diphenyl-2H-tetrazolium bromide (MTT), and 4-(2-hydroxyethyl) piperazine1-ethanesulfonic acid sodium salt (HEPES) were provided from Sigma (USA). Dimethyl sulfoxide and 3-isobutyl-1methylxanthine (IBMX) were purchased from Fluka Chemical Co. Indomethacin and human insulin were kindly provided by EXIR Company (Iran).

2.2. Preparation of Extract. The S. securidaca seeds were powdered with a blender and $860 \mathrm{~g}$ of the powder was suspended in $3200 \mathrm{~mL}$ of $70 \%$ ethanol. The mixture was left in dark at room temperature for $72 \mathrm{~h}$ under gentle shaking. The hydroalcoholic extract was then filtered and dried on a water bath.

2.3. Animals. Female albino Wistar rats $(230 \pm 30 \mathrm{~g})$ were housed in a room with controlled lighting $(12 \mathrm{~h}$ light $/ 12 \mathrm{~h}$ darkness) and temperature $\left(22 \pm 2^{\circ} \mathrm{C}\right)$. All animal studies were carried out in accordance with the ethical guidelines of the animal care of the Mashhad University of Medical Sciences, Iran. Diabetes was induced by a single intraperitoneal injection of STZ $(50 \mathrm{mg} / \mathrm{kg})$. Three days after STZ injection, induction of diabetes was confirmed by measuring fasting blood glucose (FBG). Animals were considered to be diabetic if they had FBG of $250 \mathrm{mg} / \mathrm{dL}$ or higher $[13,14]$.

2.4. Lipolysis Studies. The effect of S. securidaca extract on adipose tissue lipolysis was evaluated in ex vivo condition $[15,16]$. Retroperitoneal adipose tissues were removed from diabetic animals after seven days of STZ injection. The tissues were minced into uniform small slices of about $5 \mathrm{mg}$. The tissue slices were washed with phosphate-buffered saline, dried on the gauze, and weighted precisely. Then, tissue slices were distributed into 24 -well plate $(100 \mathrm{mg} /$ well $)$ and bathed with $1 \mathrm{~mL}$ Krebs-Ringer bicarbonate buffer supplemented with $25 \mathrm{mM}$ HEPES, $5.5 \mathrm{mM}$ glucose, and $2 \%(\mathrm{w} / \mathrm{v})$ bovine serum albumin. The tissues were treated with vehicle (basal lipolysis) or isoproterenol (stimulated lipolysis) in the absence or presence of $S$. securidaca extract under constant shaking for $90 \mathrm{~min}$ at $37^{\circ} \mathrm{C}$. At the end of the treatment, glycerol concentration was measured in the buffer by an enzymatic method.

\subsection{Preadipocyte Preparation and Adipogenesis Assay. On} day seven of diabetes inception, the rats were anesthetized with ether and retroperitoneal adipose tissue was excised through a sterile laparotomy procedure. The tissue sample was sliced into small pieces and washed with phosphatebuffered saline (PBS). The tissue pieces were then digested in PBS containing $2 \mathrm{mg} / \mathrm{mL}$ collagenase under shaking (60 cycles $/ \mathrm{min}$ ) at $37^{\circ} \mathrm{C}$. The cellular pellet was isolated via centrifugation (2000 rpm for $5 \mathrm{~min}$ ) and suspended in DMEM medium supplemented with $10 \%$ FBS, 100 units $/ \mathrm{mL}$ penicillin, and $100 \mu \mathrm{g} / \mathrm{mL}$ streptomycin. The cells were plated in culture flask and incubated in a humidified 5\% $\mathrm{CO}_{2}$ incubator until they reached confluence. The cells were then trypsinized and seeded in 12 -well plates $\left(10^{4}\right.$ cells/well). After $24 \mathrm{~h}$ of incubation, the culture medium was changed into differentiation medium (DMEM supplemented with $3 \%$ FBS, $250 \mu \mathrm{M}$ IBMX, $34 \mu \mathrm{M}$ d-pantothenate, $1 \mu \mathrm{M}$ dexamethasone, $0.2 \mu \mathrm{M}$ insulin, and $5 \mu \mathrm{M}$ indomethacin). After 3 days, the cells were exposed to the adipocyte maintenance medium (DMEM supplemented with 3\% FBS, $34 \mu \mathrm{M}$ d-pantothenate, $1 \mu \mathrm{M}$ dexamethasone, and $0.2 \mu \mathrm{M}$ insulin). The cells were further cultured in this medium for 6 days and the medium was changed every 3 days [17]. To evaluate the effects of $S$. securidaca extract on adipogenesis, both differentiation and adipocyte maintenance media were supplemented with varying concentrations of the extract or vehicle (1\% DMSO).

2.6. Oil Red O Staining. To examine the effect of S. securidaca on adipogenesis, Oil Red $\mathrm{O}$ was used to stain accumulated intracellular triglycerides in differentiated adipocytes. After 9 days of differentiation, the cells were fixed using $10 \%$ formalin and then stained by $200 \mu \mathrm{L}$ Oil Red O solution. After three times washing with distilled water, the stain was eluted from cells using $200 \mu \mathrm{L}$ isopropanol and its optical density was read at $545 \mathrm{~nm}[18,19]$.

2.7. Cell Viability Assay. Effect of S. securidaca extract on viability of isolated rat preadipocytes and L929 mouse fibroblast cells was determined using MTT colorimetric assay. The cells were seeded (5000/well) in 96-well culture plates containing DMEM medium supplemented with antibiotic and $10 \%$ FBS. After $24 \mathrm{~h}$, the medium was changed to a fresh one containing various concentrations of S. securidaca extract and the cells were further incubated for $48 \mathrm{~h}$. At the end of incubation, the MTT solution was added to each well at final concentration of $0.5 \mathrm{mg} / \mathrm{mL}$ and the plate was placed for $2 \mathrm{~h}$ at $37^{\circ} \mathrm{C}[20,21]$. Then, the supernatant was discarded and the resulting formazan was dissolved by adding $200 \mu \mathrm{L}$ dimethyl sulfoxide to each well. The absorbance of formazan dye was read at $545 \mathrm{~nm}$ against $630 \mathrm{~nm}$ as background. 


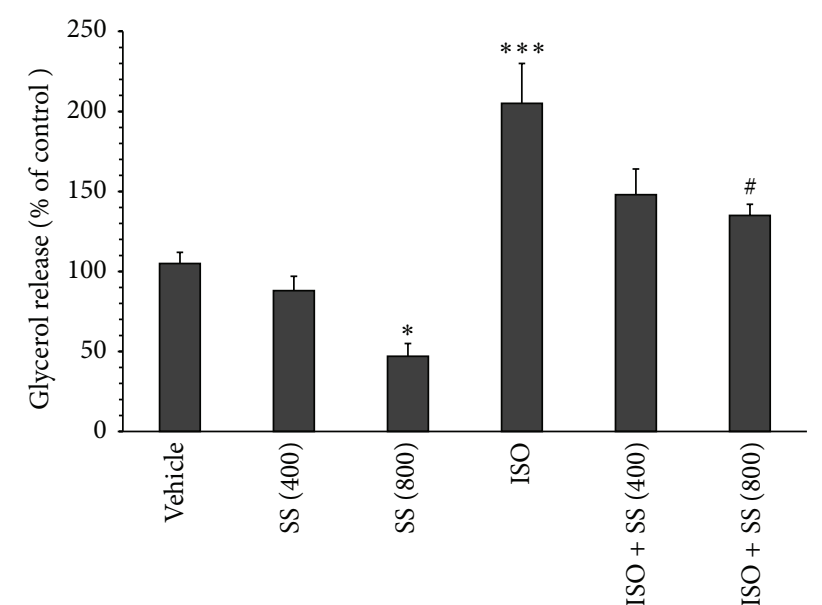

FIGURE 1: Effects of hydroalcoholic extract of Securigera securidaca on lipolysis in diabetic rats. Retroperitoneal adipose tissues were treated with vehicle or Securigera securidaca (SS) in the absence (basal lipolysis) or presence of $1 \mu \mathrm{M}$ isoproterenol (ISO) for $90 \mathrm{~min}$. Concentration of SS is shown in parentheses $(\mu \mathrm{g} / \mathrm{mL})$. Data are presented as means \pm SEM of 6 independent experiments. ${ }^{*} P<0.05$ versus vehicle; ${ }^{* *} P<0.001$ versus control; ${ }^{\#} P<0.05$ versus ISO.

2.8. Statistical Analysis. The values were compared using the one-way analysis of variance followed by Tukey's post hoc test. $P$ value $<0.05$ was considered to be statistically significant. The results are presented as mean \pm SEM.

\section{Results}

3.1. Effect of S. securidaca on Lipolysis. Figure 1 demonstrates the effect of S. securidaca extract on basal and ISO-stimulated lipolysis. In basal condition, the extract at concentration of $800 \mu \mathrm{g} / \mathrm{mL}$ significantly decreased glycerol release to $47 \pm$ $8 \%$ of control $(P<0.05)$. To examine the effect of $S$. securidaca on stimulated lipolysis, the lipolytic activity was tested in the presence of isoproterenol, a nonselective beta adrenergic receptor agonist. As expected, $1 \mu \mathrm{M}$ isoproterenol led to significant elevation in glycerol release $(205 \pm 25 \%$ of control, $P<0.001)$. The extract at concentration of $800 \mu \mathrm{g} / \mathrm{mL}$ significantly reduced the stimulated lipolysis to $135 \pm 7 \%$ of control $(P<0.05)$.

3.2. Effects of S. securidaca on Adipogenesis. Incubation of differentiating cells with $S$. securidaca extract decreased intracellular lipid droplet accumulation as evaluated with Oil Red O staining (Figure 2). The presence of 100, 200, 400, and $800 \mu \mathrm{g} / \mathrm{mL}$ of the extract in the culture medium decreased the lipid droplet content from $100 \pm 4 \%$ (untreated cells) to $75 \pm 9 \%, 86 \pm 8 \%, 78 \pm 15 \%$, and $51 \pm 3 \%(P<0.001)$, respectively.

3.3. Effect of S. securidaca on Viability of Preadipocytes. None of $S$. securidaca concentrations decreased proliferation of preadipocytes. In the presence of $50,100,200,400$, and $800 \mu \mathrm{g} / \mathrm{mL}$ of $S$. securidaca extract, viability of the cells was 97

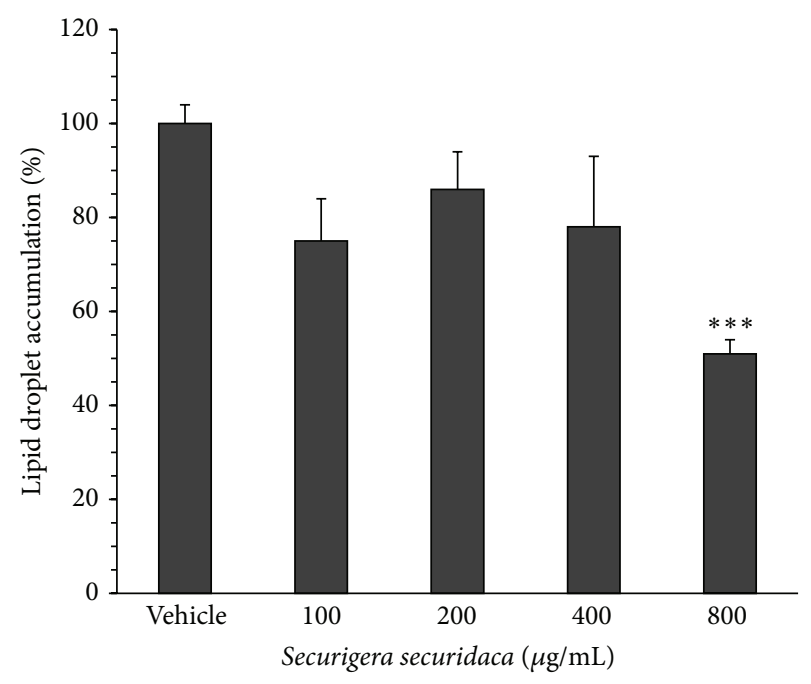

FIgURE 2: Effect of Securigera securidaca on lipid droplet accumulation in differentiating preadipocyte isolated from diabetic rats. The lipid accumulation was estimated by measuring the optical density of Oil Red O stain eluted from cells. Data are mean \pm SEM $(n=5)$. ${ }^{*} P<0.001$ versus vehicle.

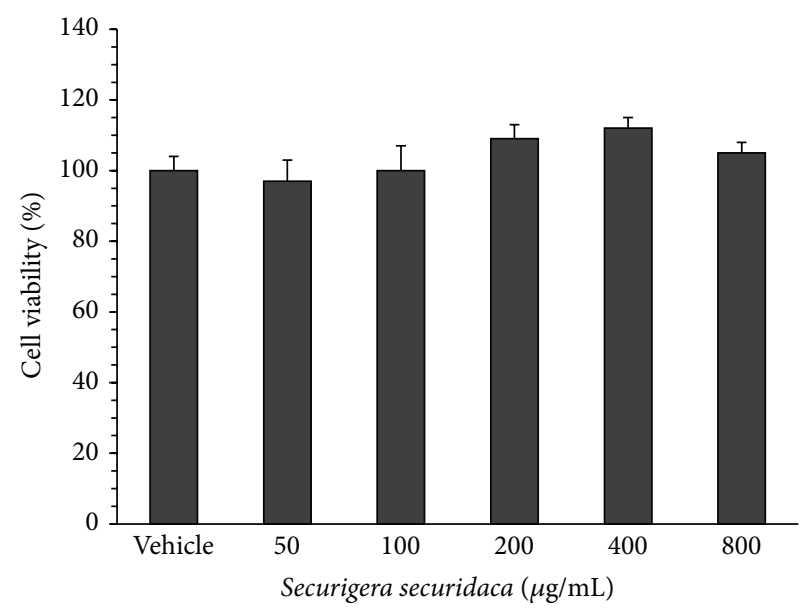

FIGURE 3: Effect of Securigera securidaca on viability of preadipocytes isolated from diabetic rats. The cells were cultured in the presence of hydroalcoholic extract of S. securidaca for $24 \mathrm{~h}$. The bars show percent of cell viability as compared with untreated cells (vehicle). Data are mean $\pm \operatorname{SEM}(n=8)$.

$\pm 6 \%, 100 \pm 7 \%, 109 \pm 4 \%, 112 \pm 3 \%$, and $105 \pm 3 \%$, respectively (Figure 3).

\section{Discussion}

Dysregulation of lipid metabolism is a key feature of some pathological conditions including diabetes mellitus, insulin resistance, obesity, and fatty liver [22, 23]. In diabetes, a spectrum of abnormalities including increased serum lipids, uncontrolled lipolysis, and dysregulation of adipogenesis and lipogenesis was involved in development of atherosclerosis and cardiovascular diseases $[2,24]$. It has been shown that 
S. securidaca reduces the serum level of triglyceride and cholesterol in hypercholesterolemic animals [11]. Also, in our previous work we showed that hydroalcoholic extract of this plant decreases serum cholesterol in diabetic rats [12]. In the present study, we further evaluated the effects of $S$. securidaca on adipose tissue in STZ-induced diabetes. Our data showed that this extract significantly decreases adipocyte lipolysis and differentiation of preadipocytes.

It has been well documented that hypercholesterolemia is associated with an increase in risks of atherogenesis in diabetes mellitus [2,25]. Because of hypocholesterolemic action, consumption of S. securidaca may improve the management of diabetic dyslipidemia and reduce the incidence of cardiovascular events in diabetic patients. Atherogenic dyslipidemia is caused by different metabolic abnormalities including (1) increased cholesterol synthesis, (2) increased production of triglyceride-rich lipoproteins, and (3) increased HDL catabolism. It is believed that among these abnormalities, the pivotal role is played by increased hepatic production of lipoproteins [2]. Availability of triglycerides within hepatocytes is an important factor influencing synthesis of very low density lipoprotein (VLDL) [26]. Triglycerides are provided from de novo synthesized or extrahepatic fatty acids. Adipose tissue-derived free fatty acid is the largest extrahepatic source of fatty acid for triglyceride synthesis [2, 27]. Fatty acids are released from adipose tissue through a highly regulated process named lipolysis. Although a variety of factors are involved in regulation of lipolysis, in physiologic situation insulin and catecholamines are the main antilipolytic and prolipolytic agents, respectively [28]. Our results showed that $S$. securidaca extract inhibits both basal and catecholaminestimulated lipolysis. Therefore, the antilipolytic action of $S$. securidaca may be responsible in part for its effect in decreasing blood cholesterol. In diabetes, deficiency of insulin in conjunction with glucagon- or catecholamine-stimulated lipolysis increases fatty acid delivery to liver which may lead to ketoacidosis, a life-threatening condition [29]. It is reasonable to conclude that $S$. securidaca can decrease the risk of ketoacidosis through inhibition of lipolysis. One limitation of our study is that we could not test more concentrations of S. securidaca on lipolysis because a limited amount of adipose tissue can be obtained from diabetic rats (the animals show rigorous weight loss).

The mass of adipose tissue is determined by the number and size of adipocytes. Number of adipocytes is dependent on the rate of formation of new adipocytes from precursor cells (adipogenesis) and the rate of adipocyte apoptosis. Size of adipocytes is increased by lipogenesis and decreased by lipolysis [30]. Our data showed that $S$. securidaca extract inhibits differentiation of preadipocyte to adipocyte. This effect in conjunction with its antilipolytic action makes $S$. securidaca a good candidate for management of diabetic dyslipidemia in obese diabetic patients. Because the $S$. securidaca extract had no effect on viability of preadipocytes, most probably its beneficial actions on lipid metabolism are not accompanied by cytotoxic effect.

In conclusion, the present study demonstrated that extract of S. securidaca seed inhibits lipolysis and adipogenesis in diabetic animals. These effects make this plant a good candidate for management of diabetic dyslipidemia and reduction of cardiovascular risk in diabetic patients.

\section{Conflict of Interests}

The authors declare that there is no conflict of interests regarding the publication of this paper.

\section{Acknowledgment}

This work is part of a Ph.D. thesis of one of the authors and is supported by a grant from Research Council of Mashhad University of Medical Sciences, Mashhad, Iran.

\section{References}

[1] A. D. Deshpande, M. Harris-Hayes, and M. Schootman, "Epidemiology of diabetes and diabetes-related complications," Physical Therapy, vol. 88, no. 11, pp. 1254-1264, 2008.

[2] M. Arca, G. Pigna, and C. Favoccia, "Mechanisms of diabetic dyslipidemia: relevance for atherogenesis," Current Vascular Pharmacology, vol. 10, no. 6, pp. 684-686, 2012.

[3] C. R. Harper and T. A. Jacobson, "Avoiding statin myopathy: understanding key drug interactions," Clinical Lipidology, vol. 6, no. 6, pp. 665-674, 2011.

[4] M. J. Sorrentino, "An update on statin alternatives and adjuncts," Clinical Lipidology, vol. 7, no. 6, pp. 721-730, 2012.

[5] M. P. Solano and R. B. Goldberg, "Management of dyslipidemia in diabetes," Cardiology in Review, vol. 14, no. 3, pp. 125-135, 2006.

[6] A. Ghorbani, "Phytotherapy for diabetic dyslipidemia: evidence from clinical trials," Clinical Lipidology, vol. 8, no. 3, pp. 311-319, 2013.

[7] A. Ghorbani, "Best herbs for managing diabetes: a review of clinical studies," Brazilian Journal of Pharmaceutical Sciences, vol. 49, no. 3, pp. 413-422, 2013.

[8] I. Ghiasi, M. R. Nikbakht, H. E. Sadeghi, V. Sabzali, S. Sabzali, and M. Shahrani, "The hypoglycemic effects of a hydroalcoholic extract from Securigera securidaca seeds on induced diabetic in male rats," Journal of Shahrekord University of Medical Sciences, vol. 8, pp. 68-73, 2007.

[9] H. Hosseinzadeh, M. Ramezani, and A. R. Danaei, "Antihyperglycaemic effect and acute toxicity of Securigera Securidaca L. seed extracts in mice," Phytotherapy Research, vol. 16, no. 8, pp. 745-747, 2002.

[10] E. Porchezhian and S. H. Ansari, "Effect of Securigera securidaca on blood glucose levels of normal and alloxan-induced diabetic rats," Pharmaceutical Biology, vol. 39, no. 1, pp. 62-64, 2001.

[11] A. Garjani, F. Fathiazad, A. Zakheri et al., "The effect of total extract of Securigera securidaca L. seeds on serum lipid profiles, antioxidant status, and vascular function in hypercholesterolemic rats," Journal of Ethnopharmacology, vol. 126, no. 3, pp. 525-532, 2009.

[12] Z. Rajaei, M. R. Hadjzadeh, R. Moradi, A. Ghorbani, and A. Saghebi, "Antihyperglycemic and antihyperlipidemic effects of hydroalcoholic extract of Securigera securidaca seeds in streptozotocin-induced diabetic rats," Advanced Biomedical Research. In press. 
[13] A. Ghorbani, G. R. Omrani, M. A. Hadjzadeh, and M. Varedi, "Proinsulin C-peptide inhibits lipolysis in diabetic rat adipose tissue through phosphodiestrase-3B enzyme," Hormone and Metabolic Research, vol. 45, no. 3, pp. 221-225, 2013.

[14] R. Shafiee-Nick, A. Ghorbani, F. Vafaee Bagheri, and H. Rakhshandeh, "Chronic administration of a combination of six herbs inhibits the progression of hyperglycemia and decreases serum lipids and aspartate amino transferase activity in diabetic rats," Advances in Pharmacological Sciences, vol. 2012, Article ID 789796, 6 pages, 2012.

[15] A. Ghorbani, G. R. Omrani, M. A. R. Hadjzadeh, and M. Varedi, "Effects of rat C-peptide-II on lipolysis and glucose consumption in cultured rat adipose tissue," Experimental and Clinical Endocrinology and Diabetes, vol. 119, no. 6, pp. 343-347, 2011.

[16] A. Ghorbani and M. Abedinzade, "Comparison of in vitro and in situ methods for studying lipolysis," ISRN Endocrinology, vol. 2013, Article ID 205385, 6 pages, 2013.

[17] A. Ghorbani, M. R. Hadjzadeh, Z. Rajaei, and S. B. Zendehbad, "Effects of fenugreek seeds on adipogenesis and lipolysis in normal and diabetic rat," Pakistan Journal of Biological Sciences, vol. 17, no. 4, pp. 523-528, 2014.

[18] A. Ghorbani, S. A. Jalali, and M. Varedi, "Isolation of adipose tissue mesenchymal stem cells without tissue destruction: a non-enzymatic method," Tissue \& Cell, vol. 46, no. 1, pp. 54-58, 2014.

[19] G. Yu, Z. E. Floyd, X. Wu et al., "Adipogenic differentiation of adipose-derived stem cells," Methods in Molecular Biology, vol. 702, pp. 193-200, 2011.

[20] S. M. Mortazavian, A. Ghorbani, and T. G. Hesari, "Effect of hydro-alcoholic extracts of viola tricolor and its fractions on proliferation of cervix carcinoma cells," Iranian Journal of Obstetrics, Gynecology and Infertility, vol. 15, no. 22, pp. 9-16, 2012.

[21] M. A. I. R. Hadjzadeh, J. Tavakol Afshari, A. Ghorbani, and M. T. Shakeri, "The effects of aqueous extract of garlic (Allium sativum L.) on laryngeal cancer cells (Hep-2) and L929 cells in vitro," Journal of Medicinal Plants, vol. 5, no. 18, pp. 41-48, 2006.

[22] P. Arner and D. Langin, "Lipolysis in lipid turnover, cancer cachexia, and obesity-induced insulin resistance," Trends in Endocrinology and Metabolism, vol. 25, pp. 255-262, 2014.

[23] E. Fabbrini, B. S. Mohammed, F. Magkos, K. M. Korenblat, B. W. Patterson, and S. Klein, "Alterations in adipose tissue and hepatic lipid kinetics in obese men and women with nonalcoholic fatty liver disease," Gastroenterology, vol. 134, no. 2, pp. 424-431, 2008.

[24] M. Lafontan, "Adipose tissue and adipocyte dysregulation," Diabetes \& Metabolism, vol. 40, pp. 16-28, 2014.

[25] O. Soehnlein and F. K. Swirski, "Hypercholesterolemia links hematopoiesis with atherosclerosis," Trends in Endocrinology and Metabolism, vol. 24, no. 3, pp. 129-136, 2013.

[26] E. A. Fisher and H. N. Ginsberg, "Complexity in the secretory pathway: the assembly and secretion of apolipoprotein Bcontaining lipoproteins," The Journal of Biological Chemistry, vol. 277, no. 20, pp. 17377-17380, 2002.

[27] S. H. Choi and H. N. Ginsberg, "Increased very low density lipoprotein (VLDL) secretion, hepatic steatosis, and insulin resistance," Trends in Endocrinology and Metabolism, vol. 22, no. 9, pp. 353-363, 2011.

[28] V. Large, O. Peroni, D. Letexier, H. Ray, and M. Beylot, "Metabolism of lipids in human white adipocyte," Diabetes \& Metabolism, vol. 30, no. 4, pp. 294-309, 2004.
[29] G. Perilli, C. Saraceni, MN. Daniels, and A. Ahmad, "Diabetic ketoacidosis: a review and update," in Current Emergency and Hospital Medicine Reports, vol. 1, pp. 10-17, 1, 2013.

[30] A. Ghorbani, M. Varedi, M. R. Hadjzadeh, and G. H. Omrani, "Type-1 diabetes induces depot-specific alterations in adipocyte diameter and mass of adipose tissues in the rat," Experimental and Clinical Endocrinology and Diabetes, vol. 118, no. 7, pp. 442$448,2010$. 


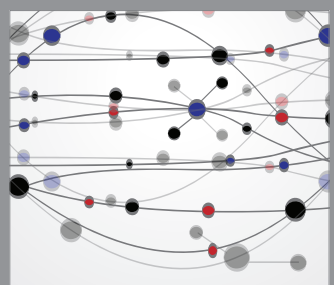

The Scientific World Journal
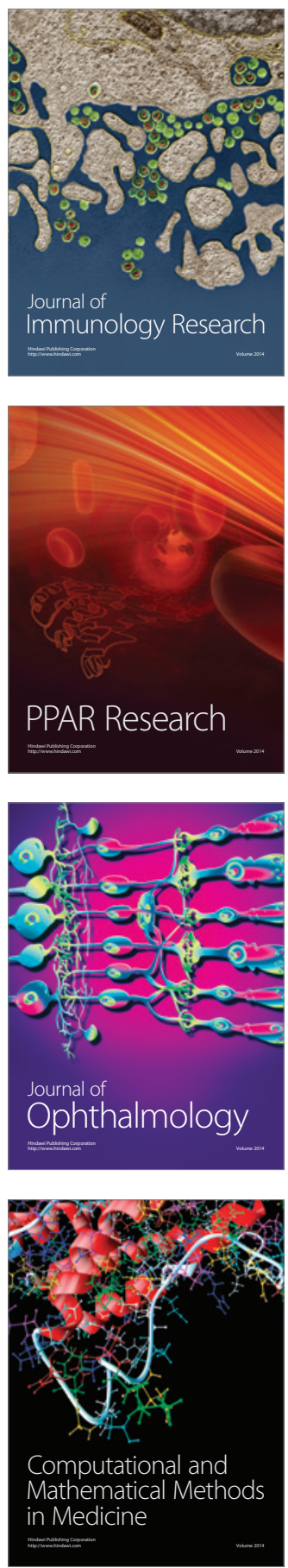

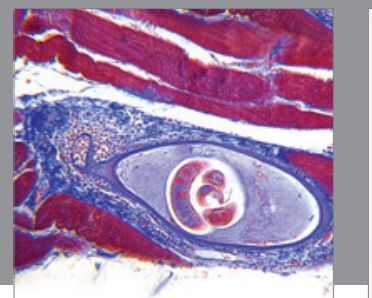

Gastroenterology

Research and Practice
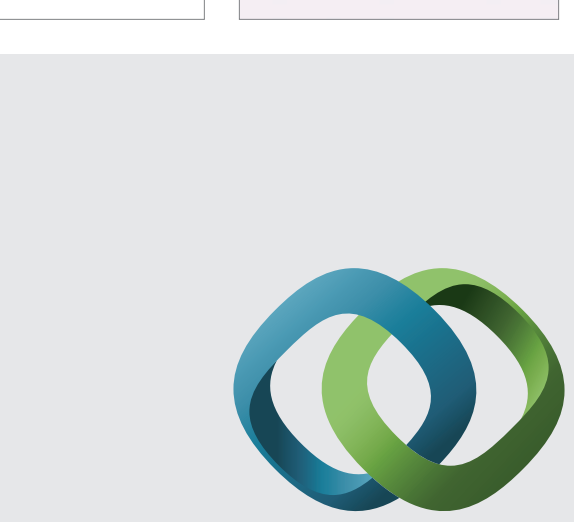

\section{Hindawi}

Submit your manuscripts at

http://www.hindawi.com
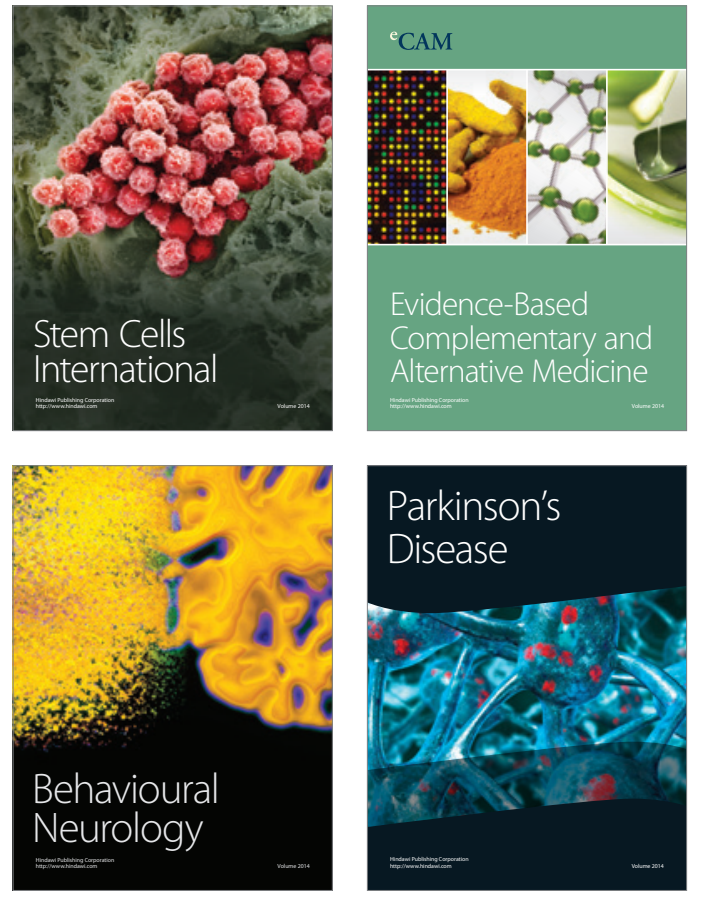
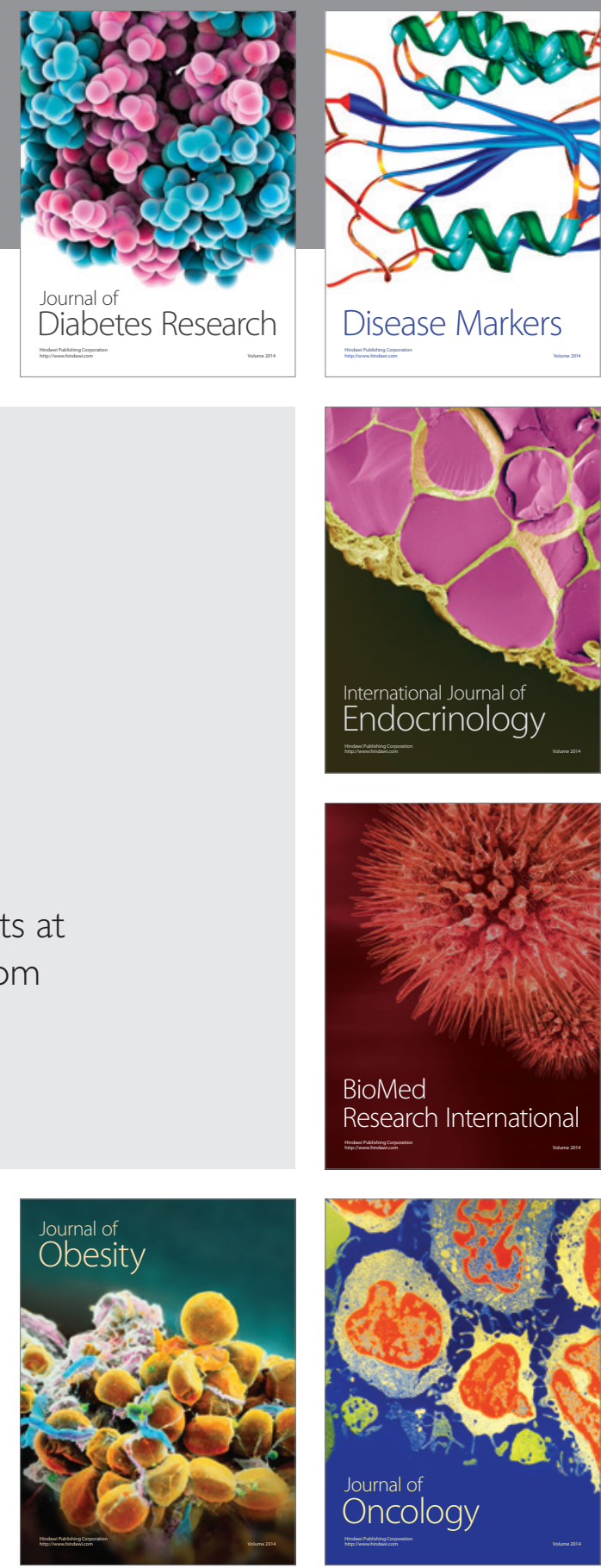

Disease Markers
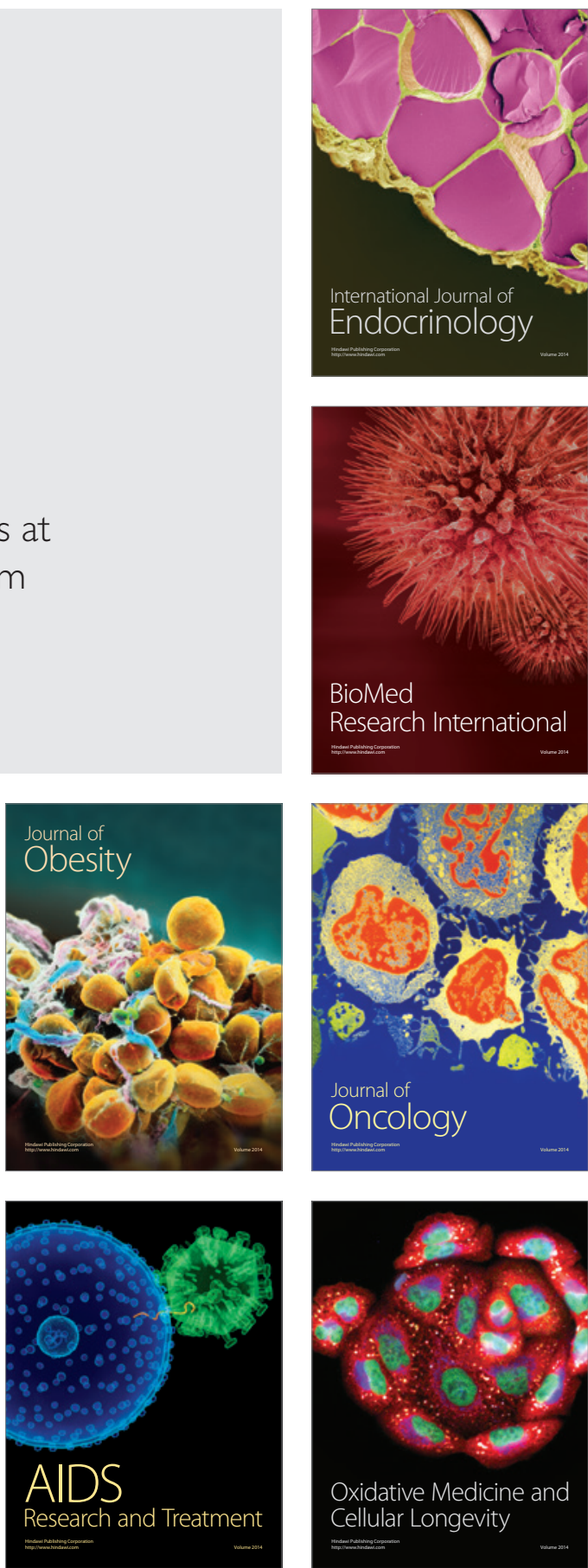